\title{
El conocimiento vernáculo como generador de desarrollo local
}

\author{
Vernacular knowledge as generator of local development
}

\author{
Hugo Alexánder Semanate Quiñonez ${ }^{1}$ \\ Felipe Andrés León Barreto ${ }^{2}$
}

\section{Resumen}

La dimensión cultural del desarrollo ha sido abordada de manera insuficiente y excluyente en términos de los postulados de la economía geográfica y del desarrollo local. Muchos fenómenos de desarrollo económico se explican desde grandes dinámicas industriales y empresariales a una escala de producción preferida por los indicadores tradicionales de crecimiento, pero el desarrollo económico a partir de una lectura tradicional y tomando sus valiosos elementos teóricos y ejercicios probatorios, da la posibilidad de evidenciar cómo las dinámicas sociales asociadas a la cultura, la tradición y lo patrimonial, son elementos generadores de aglomeraciones y de interacciones que producen un desarrollo económico local y que reclaman desde lo tradicional un espacio de desarrollo social.

Palabras clave: Cultura, clusters, desarrollo local, patrimonio, hub and spoke, vernáculo.

1 Administrador de Empresas, Universidad Nacional de Colombia. Filiación Institucional: Candidato a Magíster en Desarrollo Sustentable y Gestión Ambiental, Universidad Distrital Francisco José de Caldas. País: Colombia. Correo electrónico: alex admon@yahoo.com, hasemanateq@unal.edu.co

2 Especialista en Instrumentos de Ordenamiento Urbano Regional, Universidad Nacional de Colombia. Filiación Institucional: Candidato a Magíster en Ordenamiento Urbano Regional, Universidad Nacional de Colombia. País: Colombia. Correo electrónico: faleonb@gmail.com 


\section{Abstract}

The cultural dimension of development has been insufficiently approached in an incomplete and discriminating way as a result of the framework of economic geography and the local development theories. Some of the economic dynamics are explained from dynamics of the industrial and the business sector: the traditional visions of development and their traditional indicators, the theoretical elements, and testing exercises allow us to show how the social dynamics associated to culture, tradition and the patrimonial elements, generate clusters and interactions producing local economic development and reclaiming it from the traditionalspace of social development.

Keywords: Culture, clusters, local development, heritage, hub and spoke, vernacular. 


\section{Introducción}

El crecimiento acelerado en las ciudades ha generado una progresiva demanda por planificadores urbanos con una mirada interdisciplinaria. Este trabajo pretende abordar el desarrollo urbano dejando atrás la visión economicista en donde se ve el crecimiento de las ciudades como una necesidad para el desarrollo de la producción económica, y rescatar otros desarrollos que dinamizan las relaciones espaciales.

El tema central a lo largo del documento será la cultura vernácula como motor de desarrollo, interpretada en la generalidad de las relaciones entre el territorio y sus actores, mediante la exploración de la zona colonial en la localidad de Usaquén, en la ciudad de Bogotá. Se postula entonces que la vecindad logra generar una dinámica económica mutual, conservando un alto grado de diferenciación gracias a la preservación de una cultura propia del lugar. Sin lugar a dudas, las características que posee la localidad imprimen un sello de diferenciación al lugar, y se involucra la cultura vernácula local como un componente principal a la hora de generar desarrollo local. Sin embargo, se debe resaltar que a pesar de que el objeto de estudio tiene un alto componte histórico, que se incrusta dentro de una ciudad con rasgos modernos, se parte de la idea de Lefevbre (1978), según la cual, en la ciudad moderna se deja de vivir la ciudad histórica y queda como objeto de consumo cultural para turistas y para el esteticismo. De la misma manera, la rivalidad entre espacios públicos y espacios privados hace que dentro de la zona se configuren conflictos generados por la interacción compleja de los individuos de diferentes clases sociales.

El documento presenta una descripción básica de la localidad de Usaquén, un marco teórico de la economía regional desde la geografía económica, después expone un marco conceptual sobre la cultura vernácula, con un análisis espacial, político y socioeconómico del lugar. En particular, se analiza la importancia del capital simbólico o vernáculo, como relevante a la hora de apropiación que hacen las personas del lugar y cómo este espacio da sentido y significancia a los individuos que interactúan en dicho punto espacial urbano. Una vez identificadas las fuentes de capital se definen, desde el desarrollo local, los elementos que configuran la localidad, para finalmente sacar unas conclusiones asociadas al postulado de la existencia de esta cultura y su aporte dentro del desarrollo de la localidad.

\section{Caracterización espacial de la localidad de Usaquén}

La localidad Usaquén está ubicada en el norte de Bogotá; representa el $8 \%$ del área total de la ciudad, es la cuarta localidad en extensión total territorial con 6.531 ha y la tercera en extensión de área urbana; posee 2.720 ha de suelo rural y 290 ha de suelo de expansión. Limita por el norte con los municipios de Chía y Sopó; al sur con la localidad de Chapinero; al oriente con el municipio de la Calera y al occidente con la localidad 
de Suba. Por su posición geográfica, es considerada como una localidad de conexión entre las localidades de Bogotá y el norte de Cundinamarca (Figura 1).

Usaquén hace parte de las 21 localidades que componen la capital de nuestro país. Es divida en nueve UPZ3, a su vez, estas unidades están divididas en barrios, los cuales son: paseo los Libertadores, Verbenal, La Uribe, Toberín, San Cristóbal Norte, Los Cedros, Country Club, Santa Bárbara y Usaquén.

En términos funcionales, las economías deben ser entendidas como un sistema de producción, distribución y consumo de bienes y servicios, el cual implica un conjunto de actividades económicas organizadas por sectores de acuerdo con el tipo de procesos que se desarrollan. La composición sectorial de las actividades económicas de la localidad, revela una baja participación de la industria $(3 \%)$, frente a las actividades terciarias de comercio y servicios (97\%), (SDP, 2008).

Se pueden identificar algunos clusters potenciales en la localidad, es el caso de la fabricación de muebles como actividad representativa de la producción local. Participan las actividades de construcción, fabricación de colchones y de software y hardware, como las actividades productivas más importantes de la zona. La existencia de actividades de producción intermedia, de servicios empresariales y de comercialización asociadas a dichos productos, devela el potencial de

\footnotetext{
Unidades de Planeamiento Zonal.
}

la conformación de cluster, que de no estar activos se generarían mediante los procesos productivos que pueden lograse aprovechando el circuito de producción, servicios y comercialización.

\section{Referente teórico del desarrollo local, patrimonio y conocimiento vernáculo}

Uno de los temas que más ha recibido atención por parte de los autores de la nueva geografía económica, ha sido el de las aglomeraciones, y más precisamente el de la concentración de actividades productivas, que podrían reflejar desigualdades regionales en términos de ingresos, entre otros. Uno de los estudios más importantes es el de Krugman y Livas (1992), quienes presentan un modelo pensado para las ciudades de países en vías de desarrollo, en el cual se explica la existencia de grandes ciudades debido a la concentración de industrias dedicadas a abastecer el mercado interno. Según el modelo, a medida que las economías se van abriendo al comercio exterior, las industrias van perdiendo el incentivo de dedicarse a un único mercado, por lo que la inercia de la aglomeración se disipará.

En la actualidad, los estudios económicos están enfocados en una serie de modelos acordes a la típica teoría neoclásica, pero con desconocimiento de diferentes factores sociales, institucionales, culturales y políticos, los cuales son primordiales en la determinación del emplazamiento de una aglomeración (Martin, 1999). 
Figura 1. Información localidad de Usaquén

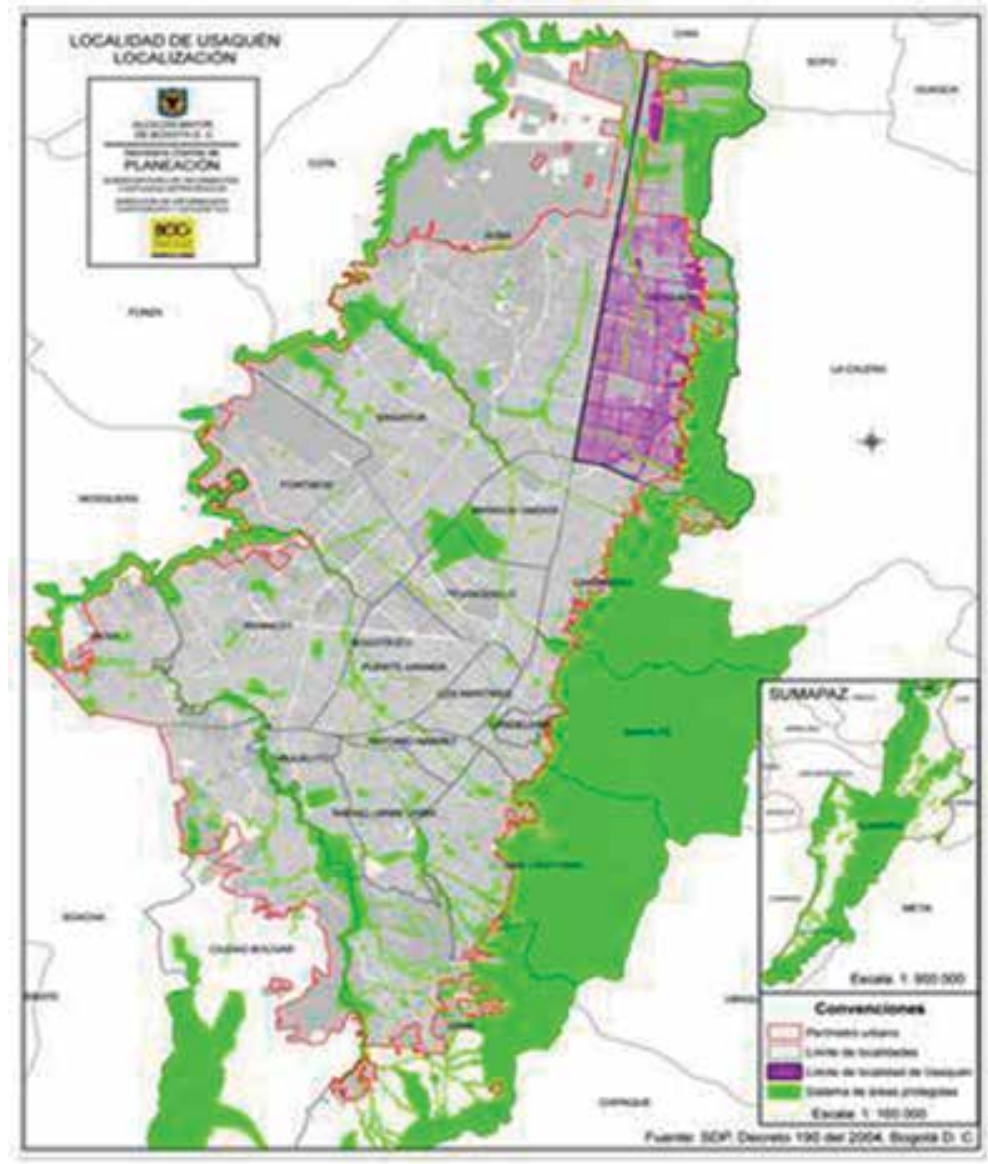

Fuente: SDP, 2008 
Tabla 1. Composición sectorial de Usaquén

\begin{tabular}{|c|c|}
\hline SECTOR & \multicolumn{1}{c|}{ DESCRIPCIÓN } \\
\hline Industria & $\begin{array}{r}\text { Se encuentra producción de bienes finales, presencia de empresas } \\
\text { constructoras, fabricación de muebles, software y hardware, fabricación de } \\
\text { colchones y publicaciones periódicas. }\end{array}$ \\
\hline Comercio & $\begin{array}{r}\text { Las actividades comerciales propias del sector terciario. La venta de calzado } \\
\text { lidera el sector, seguida por las joyerías y relojerías, la venta de muebles y la } \\
\text { venta de artículos para la decoración de interiores. }\end{array}$ \\
\hline Servicios & $\begin{array}{r}\text { Se prestan servicios empresariales y particulares. Actividades que suplen } \\
\text { los requerimientos de las empresas en materia técnica, logística y de } \\
\text { suministros. Se destacan los talleres de ornamentación, las agencias de } \\
\text { publicidad, los centros de encomienda y mensajería, así como las oficinas } \\
\text { de importaciones y exportaciones. }\end{array}$ \\
\hline
\end{tabular}

Fuente: SDP (2008).

En este sentido, la geografía y la economía se han interesado en la configuración de las ciudades y la creación de polos de atracción, tanto en las firmas como en la mano de obra, por lo que se han especificado modelos alternativos que expanden sus visiones más allá de la simple competencia perfecta y mejoran la perspectiva que tiene el economista acerca del lugar habitado.

Reconocer la importancia del espacio en la economía, es una necesidad urgente que no puede ser ajena al pensamiento económico de la actualidad; tal y como lo afirma Boisier (2005): "Está claro que el territorio no es una abstracción ni un mero piso obligado por la fuerza de gravedad, y que se convierte en una instancia simbólica hecha, no de ladrillos, sino de relaciones, lenguajes, afectos y procesos de cambio que ocurren en el territorio y no sobre él".

\subsection{Aproximaciones a la cultura vernácula}

El desarrollo local significa echar a andar el conocimiento, la inteligencia, la creatividad local, para una mejor calidad de vida de los habitantes de un barrio, comuna o localidad; esto significa valorar las potencialidades y las acciones de los autores locales (Castro, 2006, p. 166), junto con la interacción de cada uno de los miembros de la comunidad, permitiendo la generación de redes, las cuales posibilitan establecer relaciones entre el desarrollo científico-tecnológico, las actividades productivas, el sistema educativo y la cultura vernácula local.

Un desarrollo local significa partir de los recursos propios de la comunidad, como los saberes populares, ingenios, tecnologías vernáculas; en otras palabras, saberes y tecnologías socialmente apropiadas donde generalmente han resuelto 
problemas en salud, trabajo, alimentación, entre otros.

El desarrollo local a partir de la cultura vernácula, significa profundizar estos saberes y potenciar al máximo la creatividad local, abriéndola también al cambio y a la innovación. Generar procesos endógenos ascendentes en una comunidad local, significa que una sociedad local nace y renace a partir de los grupos sociales, sin embargo, las costumbres culturales de estas comunidades pueden ser afectadas por estos grupos externos.

Ahora bien, al hablar de conocimiento vernáculo $(\mathrm{CV})$ es obligatorio referirse al conocimiento, innovaciones y prácticas de las comunidades locales (término utilizado para las comunidades indígenas); dado que estas son el principal referente y las mayores generadoras de este tipo de conocimiento. Zerda (2003) propone un modelo en el que plantea mecanismos que buscan superar el choque interinstitucional entre la sociedad moderna y las comunidades indígenas. Es de esperar que este conocimiento vernáculo preserve de su extinción, reconociendo la propiedad intelectual de las comunidades locales y su participación en los beneficios económicos y no económicos, al tiempo que se facilita el uso científico y tecnológico de su conocimiento en beneficio de la sociedad global (El Tiempo, 2004, 3 de agosto).

Debido a nuevos contenidos y aplicaciones agregados por las nuevas generaciones de estas comunidades, este conocimiento está en permanente dinamismo y evolución: "el Conocimiento Vernáculo por lo tanto no es un conocimiento articulado, muerto, sino vivo, que produce innovaciones, lo tradicional en el conocimiento vernáculo no es su antigüedad, sino la manera como se adquiere y es usado por las comunidades y la sociedad" (Four Directions Counal, 1996). El CV es el producto de un sistema dinámico, el cual se conserva en el tiempo, se actualiza y tiene desarrollo al interior de los pueblos indígenas, es una parte integral de los cambios sociales y físicos, es un bien colectivo de las comunidades y fundamental para la supervivencia de esta (Zerda, 2003).

Para las comunidades locales, el conocimiento, más que una pieza aislada útil, configura todo un sistema, su forma de vida, dentro de una concepción holista4 en donde no existe separación entre hombre y naturaleza. Constituye, en esa medida, una práctica de ciencia no reduccionista, un completo sistema de innovación, donde muchas veces es propiedad de una pequeña minoría (Harrison, 1992). Entre las muchas cualidades que tiene el conocimiento vernáculo se puede observar la difícil codificación (mínimo grado), debido a que este se registra y se transmite por medio de la tradición oral.

\footnotetext{
La visión holística del mundo desde el CV: todo esta interconectado y no puede interpretarse y entenderse aisladamente. Todos los elementos de la materia tienen una fuerza de vida. Todas las partes del mundo natural y los elementos inanimados están infundidos de espíritu, por lo tanto existe una estrecha relación entre la producción de nuevo conocimiento y el incremento en la productividad, una conexión entre el sistema cultural y el económico, como circuitos interdependientes (Harris, 1994, en Zerda, 2003).
} 
Un tema particular es el de sus construcciones, infraestructura e ingenio arquitectónico, en las cuales se impregna el potencial y la experiencia generada por generaciones de su conocimiento vernáculo o tradicional, el cual es aprendido por medio de la vivencia directa y la observación; es intuitivo en su forma de pensamiento, ya que se involucra el pensamiento emocional. Además, el CV es fundamentalmente cualitativo, obtenido por medio del contacto íntimo con el medio y los recursos 5 .

\subsection{Aspectos culturales e interacciones económicas del conocimiento vernáculo dentro del patrimonio cultural}

La cultura vernácula posee unas características locales ya vistas, que aportan conocimientos asociados a la historia del lugar, a las costumbres y a las tradiciones conservadas, las cuales se convierten en un "capital" transferible dentro del comercio y el turismo, apropiando a visitantes que adquieren conocimiento y consumo cultural.

En la localidad de Usaquén de Bogotá, pueden encontrarse varias aproximaciones a lo que se llama "cultura vernácula", la cual, a nuestro juicio, es una de las principales generadoras del CV, ya que ella es la que integra y orienta todas las actividades que se generan en

\footnotetext{
Los cultivadores aborígenes tienen clara noción de las tendencias del tiempo y el espacio, de los fenómenos, tales como si una población, está creciendo o decreciendo (Wolfe, 1992, p. 17). Las comunidades indígenas hacen predicciones sobre los tipos de cultivos y qué tipo de superficie cultivar, dependiendo de las necesidades individuales y de la comunidad.
}

la integración social de la comunidad con la naturaleza y el ambiente. Este intercambio o integración al interior de las comunidades está formado por una espesa red social que lleva al desarrollo de estructuras informales muy estables (North, 1993, citado por Zerda, 2003). Las comunidades, mediante la dependencia e interacción con la naturaleza y los recursos naturales, han adquirido una inmensa cantidad de conocimiento de su entorno natural, sin embargo, el conocimiento acumulado está desapareciendo rápidamente, mientras el mundo se va volviendo cultural y biológicamente uniforme a ritmo constante.

En Usaquén se está viendo cada vez más una relación con el CV en los ámbitos relacionados con el patrimonio arquitectónico y los asentamientos temporales de comerciantes indígenas, a pesar de que en principio son más visibles los vendedores locales, estos asentamientos indígenas se observan más en el centro de la ciudad, ya que las comunidades que comercian en la Candelaria y circulan por la localidad de Santa Fe habitan cerca de la zona y tiene en su mayoría los puestos de trabajo en la calle o incluso en locales o zonas promovidas por ellos o por la Alcaldía Mayor. Estas comunidades son diferenciadas específicamente así: los indígenas Emberas Katíos ${ }^{6}$ con sus artesanías; los

6 Para las comunidades ancestrales, la vida económica es el resultado de la interacción de su cultura con el mundo natural (Dalton, 1975). La vida económica no persigue una acumulación de capital (riqueza), ni mejorar los niveles de vida de los individuos o actores de la comunidad (Sahlins, 1974), lo más importante para las comunidades es dar, compartir, regalar, y no acumular (Goldman, 1968, p. 105). 
guambianos con su medicina tradicional y artesanías; y las comunidades ecuatorianas (Kichwa-Otavalo) con sus tejidos y música. Estas comunidades configuran la localidad de Usaquén como una plataforma de expresión de cultura vernácula creada, traída, importada, la cual convive con el otro elemento, que es la cultura patrimonial asociada a la arquitectura.

$\mathrm{Al}$ respecto hay que rescatar la caracterización arquitectónica de la localidad, ya que ella se encuentra impregnada de unos rasgos significativos. Es decir, sus construcciones coloniales pueden ser vistas como generadoras de una "cultura vernácula”, dándole un valor económico, cultural y social a la localidad, siendo esta una de las localidades precursoras de las tradiciones culturales de los bogotanos y su valor patrimonial, arquitectónico e histórico para la ciudad y el país.

Usaquén es una fuente de "cultura vernácula" debido a su riqueza patrimonial $\mathrm{y}$ a las relaciones sociales que en este espacio local se generan, siendo estas características fundamentales del conocimiento vernáculo y determinantes para el desarrollo.

\section{Caracterización regional a partir del estudio individual}

Para evaluar el desarrollo regional y de aglomeración, es necesario contar con una herramienta metodológica que permita reconocer las características del cluster, tanto en el campo cuantitativo, como cualitativo. Este trabajo se basa en el análisis de las características cua- litativas de los perfiles de los diferentes agentes que interactúan dentro de la región cultural definida. Esta región sociocultural permite articular las actividades vernáculas desde una visión cultural objetiva; es decir, que esta es el sustento de la memoria colectiva y el espacio literalmente tatuado por la historia del grupo (De Almeida, 2006; Frémont, 1976; Giménez, 1994). Por tal razón, se utilizan los procedimientos metodológicos propuestos por Markusen (1994), dirigidos a implementar entrevistas cualitativas o registros institucionales para probar hipótesis acerca de la configuración de los clusters en determinada región. El autor reconoce, en primer lugar, cuatro niveles de análisis: la región, la industria o sector, la o las firmas y finalmente los informantes individuales.

En segundo lugar, propone una técnica deductiva para hallar los agentes pertinentes para realizar las entrevistas y obtener la información necesaria, y así avanzar de un nivel superior a uno menor, hasta llegar a los individuos representativos en la región. La técnica es explicada en los siguientes pasos:

De lo regional a la industria o el sector: inicia dando una definición precisa de la región que se desea estudiar, para lo cual se tiene en cuenta la situación económica de la misma, haciéndose necesario un exhaustivo estudio de cada uno de los sectores que operan allí.

Luego de la definición espacial del lugar por investigar, se rastrea la actividad de mayor importancia que se lleva a cabo 
en tal región7. Para esta tarea se puede recurrir a estadísticas ya existentes, donde se puedan contrastar, cuáles son los sectores que tienen mayor participación en las dinámicas socioeconómicas de estas regiones. También se puede llegar al sector, haciendo una revisión histórica de los antecedentes económicos y las actividades que han permitido el desenvolvimiento económico.

De la industria a la firma: después de obtener la o las actividades representativas, se buscan las firmas que tienen un papel más representativo en los clusters. Para esto se recomienda hablar con personas que estén fuera de la industria ya identificada, como autoridades locales, expertos en desarrollo económico local, historiadores empresariales y documentación sobre el tema.

De la firma a los individuos: se propone entrevistar a los administradores o especialistas dentro de cada una de las áreas de la empresa, dependiendo de la información requerida, ya que el caso es de localización, y sería de especial interés conocer la opinión de los planeadores estratégicos. También se recomienda tener la visión de otros individuos que estén fuera de la empresa y tengan vista panorámica y no sesgada sobre la organización.

Luego de localizar los individuos, en un tercer momento, se llevan a cabo las

Markusen recomienda obtener información acerca de los sectores secundarios, los cuales tienen una importancia en la configuración de los clústeres. entrevistas8 y se utiliza la información obtenida para hacer un diagrama o mapeo, donde se representa la interacción de las firmas con los competidores, proveedores y consumidores, en un ámbito regional local y otro extrarregional, tal y como lo muestra el siguiente diagrama.

Según el diagrama, las relaciones de competencia se reconocen en la parte central superior y aquellas de asociación con otras firmas se reconocen en la parte central inferior. Por otro lado, las relaciones en la cadena productiva con los proveedores y compradores están dispuestas de manera horizontal, las primeras a la izquierda y las últimas a la derecha.

El diagrama permite obtener las posibles interacciones que tiene la empresa a su alrededor, reconociendo que la característica más importante de los clusters es la cooperación que tiene tanto dentro como fuera de la región, con los distintos agentes que interactúan con la firma en cuestión, lo cual arrojaría luces sobre cuáles son las causas que mantienen a las firmas en ese espacio. Finalmente, el autor reconoce que su propuesta tiene problemas dinámicos, ya que los datos que se obtienen de la investigación son de corte transversal, lo que dificulta interpretar las coyunturas del pasado y predecir comportamientos futuros. Para solucionar este problema, se plantea una visión historicista teniendo en cuenta

El tipo de preguntas que deben ser formuladas, no se especifican en el documento, por lo que queda a discreción del investigador hacer las preguntas o encuestas necesarias para obtener la información que sea de relevancia. 
Figura 2. Mapeo de interacciones

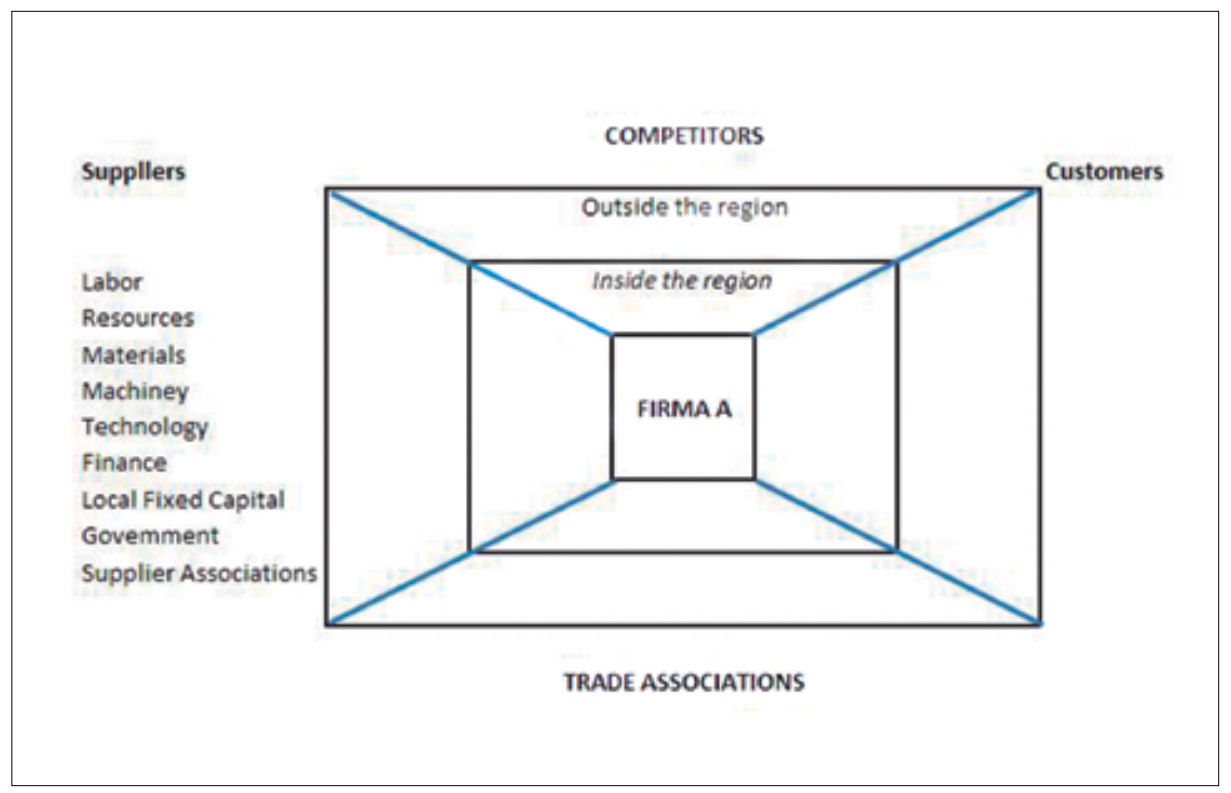

Fuente: Tomado de Markusen (1994)

aquellos sucesos pasados, que se conjugan como cambios estratégicos en las relaciones anteriormente propuestas. En este orden de ideas, se hace necesario investigar:

1. Cambios exógenos a la industria que afectaron la economía de la región, 2 . Cambios estructurales al interior de la industria, los cuales pudieron influir en los patrones de ubicación y 3. Cambios al interior de la firma, como resultado de cambios administrativos, o aquellos en la estrategia empresarial, los cuales significan una discontinuidad con las tendencias que se mantenían en el pasado.

Para entender el fenómeno de los elementos de la cultura vernácula en Usaquén, pretendemos representar esta situación en un modelo de aglomeración, donde la dinámica económica en una región sea dominada por un punto específico. Por tal razón, buscamos contrastar las características reales del emplazamiento comercial con un modelo teórico.

Para nuestro estudio, tomamos el modelo Hub-and-Spoke, propuesto en Markusen (1996): "Donde un número de firmas y/o (sic) instalaciones claves actúan como anclas o centros en la economía regional, con proveedores y actividades relacionadas extendidas alrededor de las primeras como los radios de una llanta". En este tipo de regiones, se encuentra una empresa que tiene cierto poder sobre las demás, ya sea económico o político. Esta firma se configura como el factor dinamizador de la economía de la región. Mientras 
Figura 3. Distrito Hub-and-Spoke

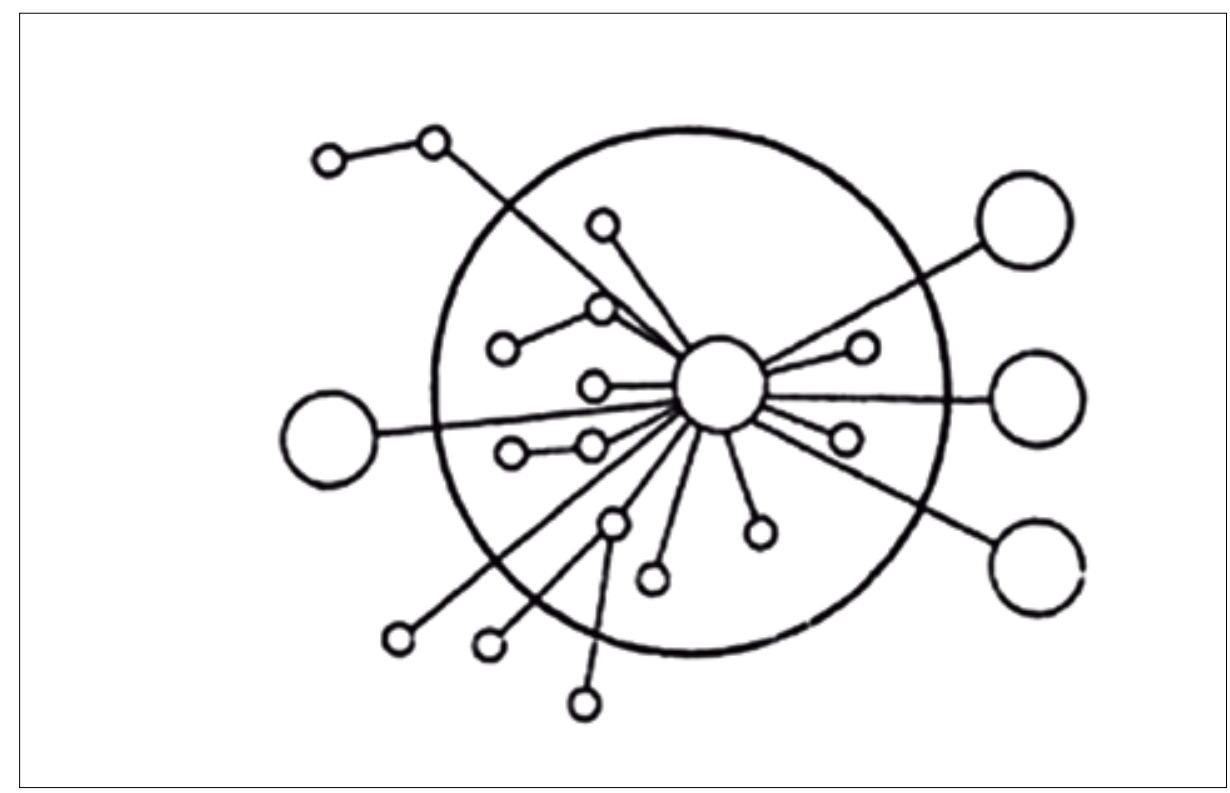

Fuente: Tomado de Markusen (1996).

que, por otro lado, se localiza otra serie de empresas pequeñas alrededor, que se benefician de las externalidades producidas por la firma de un nivel superior. Esta situación puede ser representada de la siguiente manera:

Las características principales de este tipo de análisis en la localidad de Usaquén son:

\section{Desarrollo Económico Local} (DEL) y elementos asociados a la cultura vernácula en la localidad de Usaquén

Es importante comenzar este capítulo puntualizando la revalorización del territorio como escenario efectivo de la globalización y su primacía a la hora de pensar el desarrollo. El solo hecho de que los procesos productivos se segmenten, funcional y espacialmente, sin perder eficiencia ni rentabilidad, bajo formas flexibles de territorialización -y pese a los postulados de Bossier donde los factores como el equipamiento del territorio y la descentralización, garantizan las nuevas instalaciones de estos procesos segmentados-, hace del territorio un actor relevante dentro de las nuevas formas de producción capitalista.

La importancia del territorio se observa en su rol en la competitividad imputada por la globalización en un territorio específico. Esta relevancia está dada en la medida en que el territorio es el contenedor de un stock de conocimientos originados 
Tabla 2. Caracterización a partir del modelo

\begin{tabular}{|c|c|}
\hline $\begin{array}{l}\text { Principales } \\
\text { características }\end{array}$ & $\begin{array}{l}\text { - Grandes empresas y PYMES locales-familiares (en la localidad hay una alta } \\
\text { presencia de microempresarios. Del total de empresas (18.904), } 15.194 \text { son } \\
\text { microempresas que representan el } 80 \% \text { de la localidad y el 8,7 \% de Bogotá). }\end{array}$ \\
\hline Fortaleza básica & $\begin{array}{l}\text { - Paisaje urbanístico armónico. } \\
\text { - Patrimonio cultural y turístico. } \\
\text { - Aceptable conservación del equipamiento de parques urbanos y zonas verdes } \\
\text { - Costos elevados en sus productos } \\
\text { - Flexibilidad } \\
\text { - Peso de grandes empresas } \\
\text { - Calidad del producto } \\
\text { - Diferenciación en el servicio prestado } \\
\text { - Predominio de las clases media y alta: el } 32,3 \% \text { de los predios son de estrato } 4 \text {, } \\
24,8 \% \text { estrato } 6 \text { y el } 21,1 \% \text { estrato } 3 \text {. }\end{array}$ \\
\hline $\begin{array}{l}\text { Mayor debilidad / } \\
\text { vulnerabilidad }\end{array}$ & $\begin{array}{l}\text { - Todo el conglomerado depende del desempeño de las empresas personales y de } \\
\text { unas pocas grandes. } \\
\text { - Ocupación del espacio público por vendedores informales: invasión de los } \\
\text { andenes y plazoletas por el parqueo de vehículos, especialmente, en las zonas de } \\
\text { bares y restaurantes que se encuentran ubicados en la carrera } 15 \text { entre calles } 116 \\
\text { y } 127 \text {, avenida } 19 \text {, calles } 116 \text { y } 140 \text {, Unicentro, San Cristóbal Norte y Toberín. } \\
\text { - Aun cuando se ha controlado la proliferación de ventas ambulantes y el parqueo } \\
\text { de vehículos sobre espacios públicos, se presenta invasión en andenes y áreas } \\
\text { comunales en las zonas comerciales de los barrios San Cristóbal Norte, El Toberín, } \\
\text { Santa Cecilia, Cerro Norte, Villa Nidia, Soratama, Serrezuela, Bello Horizonte, } \\
\text { Buenavista, El Codito y Delicias del Carmen. } \\
\text { - Desarrollos urbanísticos con deficientes condiciones técnicas de diseño e } \\
\text { infraestructura, ubicados en zonas de antiguas canteras o aún en explotación en } \\
\text { los cerros Orientales, propician condiciones de alto riesgo por deslizamientos. } \\
\text { - Carencia en su gran mayoría de servicios públicos por estar ubicados por } \\
\text { encima de la cota urbana (2800 msnm) y estar constituidos como asentamientos } \\
\text { ilegales. Entre estos barrios se encuentran: Bellavista, El Pañuelito, Barrancas Alto, } \\
\text { Buenavista, La Estrellita, El Cerro, Santa Cecilia y Soratama entre otros. } \\
\text { - La creciente urbanización de los cerros amenaza seriamente la sostenibilidad de } \\
\text { estos y su rol en la calidad de vida de la ciudad. } \\
\text { - Contaminación visual asociada tanto a las actividades de explotación de canteras } \\
\text { que genera deterioro del paisaje, como a la ubicación de publicidad exterior (vallas, } \\
\text { avisos, pendones, etc.) que no cumplen con las normas establecidas. Donde más } \\
\text { se presentan estas problemáticas es en las áreas comerciales de los barrios San } \\
\text { Cristóbal, Toberín y Cedritos. } \\
\text { - La localidad posee algunos segundos y terceros lugares de inseguridad, } \\
\text { mostrando una jurisdicción con mayores números de delitos, especialmente en } \\
\text { aquellos considerados contra el patrimonio. }\end{array}$ \\
\hline $\begin{array}{l}\text { Trayectoria } \\
\text { habitual }\end{array}$ & $\begin{array}{c}\text {-Estancamiento/declive (como reflejo de lo que sucede en las empresas) } \\
\text { - Innovación de productos, cambios en la distribución interna del trabajo (las } \\
\text { empresas grandes tercerizan actividades a nivel local). }\end{array}$ \\
\hline $\begin{array}{l}\text { Intervenciones } \\
\text { prometedoras } \\
\text { en términos de } \\
\text { políticas }\end{array}$ & $\begin{array}{c}\text {-Colaboración entre grandes empresas/asociaciones empresariales y organismos } \\
\text { públicos de apoyo a las PYME para su fortalecimiento. }\end{array}$ \\
\hline
\end{tabular}

Fuente: Meyer \& Harmes (2005). 
a partir del desarrollo de la cultura local. Como lo menciona Bossier, se presenta el surgimiento de la relación conocimientoterritorio, alimentado por la relaciones de asociatividad, proximidad geográfica, y transferencia de conocimiento entre los actores participantes de las dinámicas del territorio acotado como lo local, donde las aglomeraciones geográficas de industrias son un factor relevante al momento de generar el atributo de competitividad para una región, instaurando formas de desarrollo local a partir de las particularidades económicas aprovechadas desde la ventaja competitiva que da el territorio. A partir de esta relación, nace una serie de conceptos tales como clusters, tecnópolis $\mathrm{y}$ regiones inteligentes.

Siendo el desarrollo económico el objeto de las actividades socioeconómicas en la modernidad, y en el contexto de descentralización territorial, la clave para la reducción de la desigualdad y la pobreza, los gobiernos locales han adoptado como política central el desarrollo económico local y sus estrategias con el fin de superar la pobreza o ser visualizados por las dinámicas tradicionales de la economía, creando ventajas comparativas y desarrollando o explotando cualidades y particularidades en diferentes ámbitos, como el paisajístico-territorial enfocado al ecoturismo; el de la modernidad, mediante las grandes estructuras y proyectos para la promoción de negocios; el sociocultural, que atañe a este trabajo, el cual incluye la cultura patrimonial y los nichos de comercio tradicional característicos de la localidad de estudio (Usaquén).
A continuación se da un marco de definiciones en las cuales se basan las apreciaciones y relaciones entre el desarrollo local y la cultura vernácula:

El desarrollo económico local es aquel proceso reactivador y dinamizador de la economía local, que mediante el aprovechamiento eficiente de los recursos endógenos existentes de una determinada zona, es capaz de estimular el crecimiento económico, crear empleo y mejorar la calidad de vida. (ILPES, 1998)

Es un proceso participativo y equitativo que promueve el aprovechamiento sostenible de los recursos locales y externos, en el cual se articulan los actores clave del territorio para generar empleo, ingresos para mejorar la calidad de vida de la población (GTZ/DDM/ PROMOCAP, 2001 en pág. web de infopyme.com)

Se puede definir el desarrollo económico local como un proceso de crecimiento y cambio estructural que mediante la utilización del potencial de desarrollo existente en el territorio conduce a la mejora del bienestar de la población de una localidad o una región. Cuando la comunidad local es capaz de liderar el proceso de cambio estructural, la forma de desarrollo se puede convenir en denominarla desarrollo local endógeno. (Vásquez, 2007). 
Dado lo anterior, es posible notar el énfasis de las definiciones, las cuales se concentran en la actividad consciente que puede desarrollar una sociedad local, para lograr incrementos en la actividad económica y en el bienestar de la población. Podría interpretarse una intervención social prescrita para impulsar el crecimiento económico, resultante de una acción conjunta y planificada de actores privados y públicos, siendo posible distinguirla del desarrollo económico local surgido como consecuencia de la dinámica del capital, es decir, de la perspectiva del desarrollo inducido por dinámicas impropias y ajenas a lo tradicional o a lo vernáculo.

Sin embargo, es necesario identificar los factores más determinantes para el desarrollo económico local, que integran un desarrollo económico que influya en las condiciones sociales de la localidad. Según recursos de la Secretaría Distrital de Cultura Recreación y Deporte, es posible visualizar los siguientes:

- Actuación e iniciativa de los actores locales que en forma concertada (particularmente pública-privada) impulsan programas y proyectos económicos.

- La intensificación y diversificación productiva con alta generación de empleo;

- Entes generadores de condiciones infraestructurales (en primer lugar gobiernos nacionales y municipales);

- Apertura de circuitos de toda la cadena productiva;
- Financiamiento, capacitación, organización asociativa;

- Asistencia técnica y financiera e incorporación tecnológica a MIPYMES;

- Reglas de juego claras en actores involucrados;

- Marco jurídico que asegura la inversión y el derecho a la propiedad.

- Suficiente información del mercado;

- Elevación de estándares de calidad;

- Sujeción a los derechos laborales establecidos;

- Una rigurosa protección y consideración del ambiente.

Los gobiernos municipales tienen un rol supremamente importante en la promoción y facilitación del desarrollo económico local y la prestación y garantía de los espacios públicos, para desarrollar las actividades y mantener tanto el patrimonio como escenario tradicional como los procesos participativos para la gestión, organización y promoción de eventos que alimentan y autentican la cultura vernácula.

La cultura vernácula se encuentra en la dimensión del desarrollo económico local correspondiente a lo territorial: el cual se produce en un espacio geográfico delimitado por características físicas, socioculturales y económicas particulares. Su impulso obliga a identificar diferentes territorios para que las iniciativas respondan a las características específicas y la vocación económica. También la cultura vernácula se encuentra en la dimensión sociocultural, que 
pone énfasis en las personas que actúan en una zona determinada, sus formas de relacionarse, los patrones culturales y los valores que constituyen la base para impulsar las iniciativas DEL. Finalmente podemos ubicar la cultura vernácula en la dimensión institucional, integrada por las organizaciones privadas y públicas, las organizaciones sociales y comunales existentes en el territorio, sus relaciones, procedimientos y reglas de actuaciones, así como la normatividad que tiene como función el gobierno nacional y municipal. Además, lo institucional también se relaciona con la existencia de reglas del mercado y su función reguladora del sistema económico local.

Los actores principales del desarrollo económico local desde la cultura vernácula, que son claves de la dinámica de desarrollo social:

- La comunidad ofertante y demandante.

- Emprendedores locales.

$:$

- Gobierno municipal y la red patrimonial y de espacio público.

:

- Administración pública desconcentrada y descentralizada- gobierno local.

- ONGs con enfoque económico y de servicios empresariales.

$\bullet$

- Universidades y centros de investigación.

Cada uno de ellos aporta de diferente manera al desarrollo económico y social.
La principal función de estos actores es mantener una dinámica socioeconómica sustentada en las prácticas tradicionales de la localidad y de la zona específica de desarrollo.

En este sentido, siendo el desarrollo local una estrategia definida por los gobiernos municipales, la cultura vernácula entendida desde lo territorial como un sistema de conocimiento local, autóctono, tradicional que se caracteriza y se distingue en el entorno social, se convierte en una de las fuentes del desarrollo local que promueve la inclusión, la pluralidad y el conocimiento autóctono, además de la restitución de identidad territorial con una dinámica subsidiaria de la economía formal y de calle.

A continuación se hará un barrido de las dinámicas patrimoniales, comerciales y paisajísticas que alimentan la producción de visualización de la cultura tradicional de la localidad de Usaquén, sujeto y objeto de dinámicas económicas asociadas al turismo colonial, al comercio artesanal y al consumo cultural, por parte del arte, la música etc.

La localidad de Usaquén tiene importantes procesos culturales identificados mediante el diagnóstico cultural construido participativamente con los agentes que integran el sistema local cultural. Usaquén es un punto de referencia cultural y turística a nivel distrital, nacional e internacional. En esta localidad, cuya población pertenece a los seis estratos socioeconómicos, existe un gran movimiento cultural y artístico en su mayoría no 
articulado y que en general no participa de los procesos culturales que se producen desde lo estatal. Por otro lado, desde los procesos que se adelantan siguiendo las directrices de lo estatal, encontramos que si bien Usaquén no es de las localidades abanderadas en el tema, no obstante podemos decir que ha ganado un espacio importante en cuanto a participación de procesos se refiere, fortaleciéndose cada vez más en ello.

Entre las instancias de participación y representación que existen en la localidad y que cuentan con reconocimiento en el tema cultural, existe la Mesa de la Cultura: espacio paralelo al Concejo Local de Cultura y que tiene representación en las reuniones en este último; la Corporación de Artistas de Usaquén, que adelanta lo referente a la Casa de la Cultura de Usaquén, haciendo un aprovechamiento de los espacios de circulación existentes en la localidad y visibilizando la producción de los grupos y artistas locales; por último se encuentra el espacio del Consejo Local de Cultura, que se ha empoderado $\mathrm{y}$ tiene reconocimiento e incidencia en el ámbito político, en la implementación de proyectos, recursos y otros, a nivel local.

En general, la cultura para los habitantes de Usaquén es un tema importante en todos los estratos, y se encuentran varios ejemplos, como el resultado de la encuesta de consumo cultural realizada por el Observatorio de Cultura de Bogotá, que indicó que los habitantes de Usaquén de los estratos 4,5 y 6 , son los que más invierten en consumo cultural; otro ejemplo es el hecho que la cultura ha actuado como un agente facilitador en la organización de artistas, también ha permitido la integración de la población de Usaquén alrededor de los proyectos locales y distritales, y que cada vez más haya un interés de participar en los procesos existentes.

\subsection{Elementos patrimoniales históricos asociados al desarrollo}

El inventario de lugares patrimoniales y de atractivo turístico que reproducen la cultura vernácula como fuente de desarrollo económico local, fue tomado de las páginas web institucionales de la localidad y del distrito capital:

Plaza de Usaquén: corresponde a lo que fue la antigua plaza principal del pueblo de Usaquén. Una amplia área se encuentra cubierta por ladrillo, en pequeños sectores se encuentra prado y tiene una arborización con especies como el urapán, eucalipto y liquidámbar. Camellones en piedra, amoblamiento de sillas, faroles, juegos para niños y cancha múltiple. Conserva pila tallada en piedra y un busto en yeso del General Simón Bolívar. (Pág. web Bogotá.gov.co)

\section{Casa de Hacienda Santa Bárbara:} construida en 1847, hasta 1920 fue un importante centro de la vida social y económica de la ciudad. La casa está conformada por dos cuerpos: el costado sur, la casa de residencia de dos pisos, en el centro de la fachada de la casa se encuentra el portal de piedra que marcaba la entrada; el costado norte, el tramo que en su función original albergaba los servicios de la casa. 
Casa de la Alcaldía de Usaquén: construcción que data de la época colonial y conserva el corredor exterior y los pies derechos apoyados sobre pilastras en piedra que sostienen el alero de la cubierta a dos aguas con teja de barro de media caña.

Estación del Ferrocarril de Usaquén: hace parte del conjunto del orden nacional de las estaciones de pasajeros del ferrocarril de Colombia. La edificación de dos pisos conserva el andén techado en el que esperaban o se recibían los pasajeros.

\section{Iglesia de Santa Bárbara de Usaquén:} data de 1665; se destaca en el interior el retablo en madera tallada y dorada que se ha fechado de la mitad del siglo XVIII, conserva cuadros de la misma época y de autores anónimos, entre los que sobresalen la Crucifixión y la Anunciación de María.

La Kermesse - Hotel La Fontana: cada domingo y durante todo el día, se desarrolla un mercado en el que se exhiben y comercializan productos artesanales, obras de arte y artículos de vestir. En el Hotel La Fontana se encuentra La Kermesse, único mercado de objetos y artesanías de Bogotá; brunch dominical; comidas rápidas; menú infantil; talleres creativos gratuitos para los niños; exposiciones de pintura y escultura.

Mercado de las Pulgas Toldos de San Pelayo: en este mercado se exhiben y comercializan objetos artesanales, an- tigüedades, comidas típicas y prendas de vestir. Los Toldos de San Pelayo se iniciaron en junio de 1991, por una convocatoria de la alcaldesa de Usaquén, quien quería darle en ese momento a la zona un aspecto cultural.

Mercado de las Pulgas Carpe Diem: en este mercado se exhiben y comercializan productos alimenticios, de vestir y adornos elaborados de manera artesanal. También se encuentran objetos antiguos utilitarios o de adorno. Los domingos y lunes festivos Carpe Diem reúne a artistas, artesanos, anticuarios y gastrónomos, para hacer un lugar de ensueño, enmarcado por los cerros orientales en los que la fauna y flora nativa forman un pulmón que refresca y genera paisaje inspirador.

\subsection{Diagrama de interacciones}

Las anteriores observaciones se representan en el siguiente diagrama de interacciones. Las relaciones vitales encontradas son representadas con líneas solidas, mientras que aquellas de menor importancia se representan mediante una línea discontinua.

El diagrama muestra las interacciones que existen en Usaquén, específicamente en el centro colonial de la localidad. Se observa que la principal competencia de los comerciantes de esta localidad, es la localidad de la Candelaria, ya que esta maneja el mismo tipo de cultura vernácula, seguida por Chapinero y Suba en una escala menor. 
Figura 4. Mapeo de las interacciones de la localidad de Usaquén

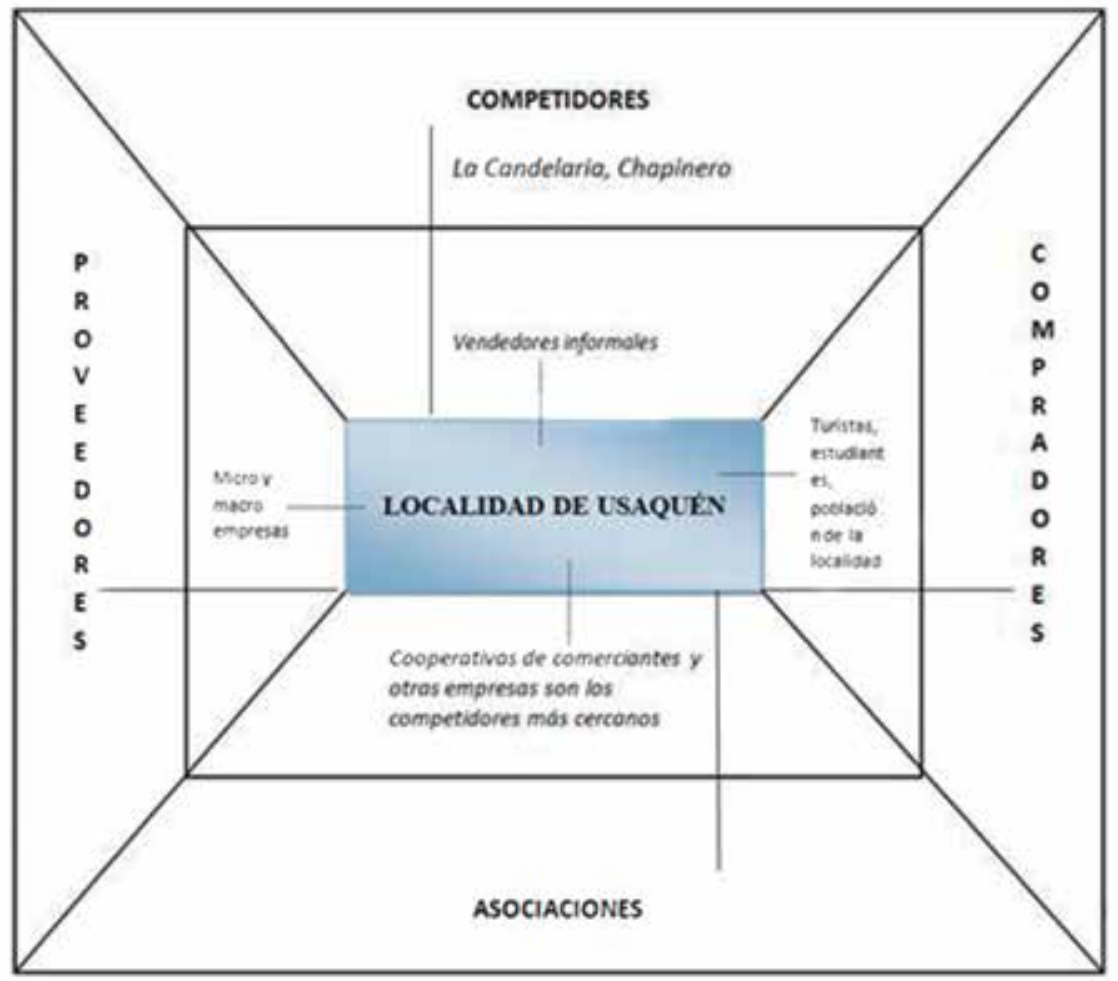

Fuente: Los autores, a partir de Markusen (1996).

Los principales compradores encontrados en la localidad son turistas, comerciantes y jóvenes estudiantes. El sector empresarial de la localidad está catalogado por empresas familiares que se sostienen de la prestación de servicios (hoteles, restaurantes, joyerías).

Las interacciones socioeconómicas que se dan en la zona colonial, están ligadas en su mayoría al comercio de pequeños propietarios. Existe un proceso de formalización de sus economías y prácticas, que ha llevado a la construcción de una aglomeración comercial, artesanal y gastronómica alrededor de atractivos materiales que soportan la dinámica patrimonial. De este modo se visualiza el aprovechamiento del mismo y el interés por el orden promulgado en las actividades, sumado a la pacífica interacción entre el turista, el visitante poblador y el comerciante artesanal.

\section{Conclusiones}

La cultura vernácula es un eslabón importante para la economía, pero no es la más reconocida. La importancia econó- 
mica del sector cultural se produce de forma indirecta mediante, por ejemplo, las rentas que genera el turismo cultural en empresas de hostelería, restauración y servicios, o de las rentas inmobiliarias que derivan del aumento del precio del suelo, gracias al desarrollo de infraestructuras o espacios culturales.

La cultura vernácula se puede catalogar como una máquina de producción de externalidades que benefician a varios sectores, los cuales de forma indirecta pueden reconocer esta deuda. Por esta razón, buena parte de los beneficios que genera la cultura son capitalizados en otros puntos de las economías urbanas.

Según esta gramática económica, las ciudades concurren entre sí para ganar la titularidad de capital cultural o para adquirir los servicios de arquitectos estrella que diseñen los nuevos iconos urbanos destinados a "modernizar" la imagen postal de la ciudad. Se invierte en grandes complejos culturales sabiendo que estos serán excelentes motores de la "regeneración urbana".

El conocimiento y la cultura vernácula contribuyen a "culturizar" la economía y a dotarla de nuevos imaginarios, sonidos y signos de identidad, siendo así un falso sector estratégico. Bajo estas perspectivas, estas empresas no son productivas en sí mismas, solo contribuyen a mejorar la productividad de otros sectores económicos que orbitan a su alrededor.

Convertidas en empresas, las comunidades se ven obligados a valorizar, capitalizar y explotar sus saberes, a poner a trabajar sus redes de contactos, a apropiarse y vender los conocimientos colectivos y, en definitiva, a operar bajo lógicas que les son del todo ajenas, y que, no obstante, son las que definen el funcionamiento de los mercados culturales.

Para analizar los elementos que generan desarrollo local en la localidad de Usaquén, es necesario profundizar en la investigación local comportamental; hay que extraer e identificar cada vez más, tanto las particularidades consideradas cultura vernácula como sus aportes a la dinámica económica local.

En este sentido, la localidad de Usaquén -y específicamente la zona tradicional de alrededores de la plaza, el parque, la estación del tren y la hacienda-, presenta, en primera instancia, elementos arquitectónicos, espaciales y emblemáticos que traen y atraen turistas de la ciudad, vecinos y turistas del país e incluso extranjeros que ven en la zona no solo un escenario de descanso, de observación y relación si no un atractivo arquitectónico que se funde con los cerros orientales dándole un valor paisajístico, convirtiendo el lugar de manera paralela en un centro cultural del norte de la ciudad, donde se expresan múltiples relaciones culturales locales e interlocales.

Este escenario anterior se convierte entonces en ideal para que diferentes fenómenos culturales se concentren y para que dinámicas contemporáneas se conviertan en tradicionales, como el comercio artesanal -observado en los 
dos mercados de las pulgas-, sumado a la presencia y coexistencia de las comunidades indígenas ya mencionadas (Embera, Guambíos, Kichwa-Otavalo) $\mathrm{y}$, por supuesto, a los habitantes mismos que hacen del comercio un impulso para el desarrollo local de la zona mediante la explotación de riquezas tradicionales de las comunidades y de actores locales. 


\section{Literatura citada}

Alcaldía Mayor de Bogotá. (2011). Recuperado de http://www.bogota.gov.co

Boisier, S. (2005, agosto). ¿Hay espacio para el desarrollo local en la globalización? Revista de la CEPAL, (86).

Castro, B. (2006, primer semestre). La educación: potencialidades y dificultades en el desarrollo local y regional. Sociedad Hoy, (10), 155-180. Universidad de Concepción, Chile.

CEPAL \& GTZ (2000). Descentralización y desarrollo económico local una visión general del caso de Colombia proyecto CEPAL/GTZ "desarrollo económico local y descentralización en América Latina”. Santiago, Chile.

Dalton, G. (1975). Study of Agricultural Systems. UK: Elsevier.

De Almeida, M. (2006). La creación de regiones turísticas y el desarrollo local en el espacio brasileño. IESA. Cuadernos de Geografía, (15). Del Departamento de Geografía, Facultad de Ciencias Humanas, Universidad Nacional de Colombia.

El Tiempo. (2004, 3 de agosto).

Frémont, A. (1999). La region. Espace vécu. Paris: Flammarion.

Four Directions Council Forests. (1996). Indigenous Peoples and Biodiversity: Contribution of the four Directions Council. Submission to the Secretarial for the Convention on Biological Diversity. Citado por G. Dutfiel (2000). The Public and Private Domains: Intellectual Property Rights in traditional Knowledge. Working paper. (Page 8). Oxford: Oxford University.

Giménez, G. (1994). Apuntes para una teoría de la región. Culturas Contemporáneas 6(18), 165-173.

Goldman, I. (1968). Los Cubeo. México: Instituto indigenista Interamericano.

Harris, D. (1994). Endogenous Learning and Economic Growth. En M. Carnoy. Economics of Education. Stanford, California: Stanford University.

Harrison, S. (1992). Ritual as Intellectual Property. Man, (27).

Krugman, P. \& Livas, R. (1996). Trade policy and the third world metropolis. Journal of Development Economics. 
Lefevbre, H. (1978). El derecho a la ciudad. S.1.: Península.

ILPES Instituto Latinoamericano y del Caribe de Planificación Económica y Social. (1998). Manual de desarrollo local. Santiago: ILPES.

Infomipyme. (2011). El rol del gobierno municipal en el desarrollo económico local. Recuperado de http://www.infomipyme.com/Docs/GT/sidel/municipal/ConsideracionesConceptuales.htm

Markusen, A. (1996). Sticky Places in Slippery Space: A Typology of Industrial Districts. Economic Geography, 72 (3), 293-313.

Markusen, A. (1994). Studing Regions by Studing Firms. Profesional Geographer, 46 (4), 477-490.

Meyer, J. \& Harmes, U. (2005) Como Promover. Clusters. Documento de trabajo. Recuperado de: www.mesopartner.com

Martin, R. (1999). The new geographical turn in economics: some critical reflections. Cambridge Journal of Economics, (23), 65-91.

North, D. (1993). Instituciones, cambio institucional y desempeño económico. México: Fondo de Cultura Económica.

Sahlins, P. (1974). Stone Age Economics. Cambridge: Cambridge University Press.

Secretaría Distrital de Planeación (SDP) \& Instituto de Estudios Urbanos (IEU) de la Universidad Nacional de Colombia. (2008). Caracterización localidad de Usaquén. Georeferenciación de la inversión local 2004-2007. Bogotá: s.n.

Vázquez, B. (2007) Desarrollo endógeno. Teorías y políticas de desarrollo territorial. Investigaciones regionales, 11, 183-210.

Zerda, A. (2003). Derechos de Propiedad Intelectual Sobre el Conocimiento Vernáculo. Análisis y propuesta desde la economía institucionalista. Bogotá: Universidad Nacional de Colombia, Facultad de Ciencias Económicas.

Recepción: 30 de noviembre de 2012

Evaluación: 30 de julio de 2012

Aprobación: 10 de octubre de 2012 